\title{
Integrated Use of Pyraclostrobin and Epoxiconazole for the Control of Fusarium Head Blight of Wheat in Anhui Province of China
}

\author{
Yu Chen, Ai-Fang Zhang, Tong-Chun Gao, Yong Zhang, and Wen-Xiang Wang, Institute of Plant Protection, Anhui Academy of \\ Agricultural Sciences, Hefei 230031, China; and Ke-Jian Ding, Li Chen, Zhong Sun, and Xin-Zhou Fang, College of Plant \\ Protection, Anhui Agricultural University, Hefei 230036, China; and Ming-Guo Zhou, College of Plant Protection, Nanjing
} Agricultural University, Nanjing 210095, China

\begin{abstract}
Chen, Y., Zhang, A.-F., Gao, T.-C., Zhang, Y., Wang, W.-X., Ding, K.-J., Chen, L., Sun, Z., Fang, X.-Z., and Zhou, M.-G. 2012. Integrated use of pyraclostrobin and epoxiconazole for the control of Fusarium head blight of wheat in Anhui Province of China. Plant Dis. 96:1495-1500.

Fusarium asiaticum and $F$. graminearum are the primary causal agents of Fusarium head blight (FHB) of wheat in China. Carbendazim (a benzimadazole fungicide, MBC), has been extensively used for the control of FHB, resulting in severe MBC resistance in China. This article presents the baseline sensitivity of $F$. asiaticum and $F$. graminearum isolates from Anhui Province of China to fungicides pyraclostrobin (a quinone outside inhibitor) and epoxiconazole (a sterol demethylation inhibitor). In the presence of salicylhydroxamic acid, the $50 \%$ effective concentration $\left(\mathrm{EC}_{50}\right)$ values for pyraclostrobin in inhibiting mycelial growth of the $126 \mathrm{~F}$. asiaticum isolates and $63 \mathrm{~F}$. graminearum isolates were 0.012 to $0.135 \mu \mathrm{g} / \mathrm{ml}$ and 0.010 to 0.105 $\mu \mathrm{g} / \mathrm{ml}$, and the $\mathrm{EC}_{50}$ values for pyraclostrobin in inhibiting conidium germination of the $F$. asiaticum and $F$. graminearum populations were 0.047 to 0.291 and 0.042 to $0.255 \mu \mathrm{g} / \mathrm{ml}$, respectively. The $\mathrm{EC}_{50}$ values

F. graminearum populations were 0.12 to 0.95 and 0.16 to $0.93 \mu \mathrm{g} / \mathrm{ml}$, respectively. All of the baseline sensitivity curves were unimodal. This study also suggested that there was no cross-resistance between MBC and pyraclostrobin or epoxiconazole. In the protective and curative tests, pyraclostrobin and epoxiconazole applied at 200 and $300 \mu \mathrm{g} / \mathrm{ml}$ exhibited over $75 \%$ protective and curative control efficacy in all treatments. In field trials, both pyraclostrobin and epoxiconazole at $225 \mathrm{~g}$ a.i./ha provided over $80 \%$ efficacy in 2010 and 2011 at both sites where MBC resistance occurred, suggesting excellent activity against FHB. Interestingly, integrated use of pyraclostrobin + epoxiconazole applied at $150+150 \mathrm{~g}$ a.i./ha provided over $85 \%$ efficacy at both sites in 2010 and 2011. Pyraclostrobin and epoxiconazole should be good alternatives to $\mathrm{MBC}$ for the control of $\mathrm{FHB}$, and integrated use of these two fungicides might achieve greater efficacy.
\end{abstract} for epoxiconazole in inhibiting mycelial growth of the F. asiaticum and
Fusarium head blight (FHB) is a devastating disease of cereals which can cause huge losses in epidemic years, becoming a major threat to the wheat and barley industry worldwide, and is responsible for extensive damage to wheat in humid and semihumid regions of the world (2). In China, FHB generally occurs in the middle and lower reaches of the Yangtze River, the Huaihe River Valley, and the eastern coastal region (6). However, an increase in the disease in the northern and western wheat-growing areas of China has occurred in the last decade (6). FHB not only results in 5 to $15 \%$ loss of grain yield in years of moderate epidemic and up to $40 \%$ in years of severe epidemic but also causes a decrease in grain quality because of the production of mycotoxins such as deoxynivalenol, nivalenol, and zearalenone $(3,20,22)$. Although a number of Fusarium spp. can cause FHB, the primary etiological agents of this disease belong to the Fusarium graminearum species complex of B-trichothecene toxin producers, which contain at least 11 phylogenetic species, including $F$. acaciae-mearnsii, $F$. asiaticum, $F$. austroamericanum, $F$. boothii, $F$. brasilicum, F. cortaderiae, $F$. gerlachii, F. graminearum, $F$. meridionale, F. mesoamericanum, and $F$. vorosii $(18,21,25,27)$. Different Fusarium spp. may be associated with FHB in different regions of the world because of different cropping systems and climatic conditions $(17,26)$. In China, F. asiaticum and $F$. graminearum are the major causal agents of FHB, although other Fusarium spp. (such as F. cul-

Corresponding authors: W.-X. Wang, E-mail: wwxjxm@tom.com and M.-G. Zhou, E-mail: mgzhou@njau.edu.cn

Y. Chen and A.-F. Zhang share joint first authorship.

Accepted for publication 18 April 2012.

http://dx.doi.org/10.1094/PDIS-01-12-0099-RE

(C) 2012 The American Phytopathological Society morum, $F$. avenaceum, and $F$. tricinctum) were also isolated occasionally from infected wheat heads (27). In a previous study, in total, 299 isolates collected from various epidemic regions of China were analyzed and the results showed that 231 isolates (77.3\%) belonged to $F$. asiaticum and the remaining 68 isolates were $F$. graminearum (31). These two species are also predominant in the populations of FHB pathogens in Japan (23).

To control FHB, fungicide sprays have been used during the last few decades because only a few cultivars were resistant to $F$. graminearum isolates. In the past 30 years, carbendazim (MBC) has been the major fungicide for FHB control in China, especially in Anhui Province. However, the effectiveness of $\mathrm{MBC}$ has been threatened by the emergence of resistant pathogen populations in the field $(4,7,8)$.

Fungicide application is most effective at wheat anthesis, the time of primary infection. Applications of fungicides with a mode of action alternative to $\mathrm{MBC}$ would be necessary for management of $\mathrm{MBC}$ resistance in FHB. The sterol demethylation inhibitor (DMI) fungicides inhibit the sterol C-14 $\alpha$-demethylation of 24methylenedihydrolanosterol, a precursor of ergosterol in fungi (27). DMIs comprise a large number of commercially successful fungicides and were first used in agriculture in the 1970s. Many field studies showed that DMI fungicides such as tebuconazole and epoxiconazole are effective against Fusarium spp. (14,15). Pyraclostrobin, belonging to a relatively new group of fungicides, quinone outside inhibitors (QoIs), had been introduced for use on fruit and vegetables in China. DMIs and QoIs have a broad spectrum of activity against a large number of fungal pathogens on various crops. Both of the fungicide classes mentioned have modes of action different from that of MBC. No fieldwork has been reported evaluating the application of the mixture of pyraclostrobin and epoxiconazole for the control of FHB.

The objectives of this study were to (i) establish the baseline sensitivity of $F$. asiaticum and $F$. graminearum isolates to pyraclostrobin and epoxiconazole using the field isolates from Anhui 
Province of China, (ii) determine the cross-resistance patterns between MBC and pyraclostrobin or epoxiconazole, (iii) investigate the protective and curative activity of the two fungicides against FHB, and (iv) test the efficacy of pyraclostrobin and epoxiconazole in controlling this disease.

\section{Materials and Methods}

Fungicides and media. Pyraclostrobin (25\% Cabrio, EC) and epoxiconazole (12.5\% Opus, SC) were provided by BASF Co., China and were dissolved in sterile water to $1.0 \mathrm{mg} / \mathrm{ml}$ for the stock solution. Potato sucrose agar (PSA) was used in isolating and storing the tested isolates. Mung bean broth (MBB), 1 liter of $\mathrm{H}_{2} \mathrm{O}$ amended with $50 \mathrm{~g}$ of mung bean, was used in producing conidia. Water agar (WA) medium was consisted of $20 \mathrm{~g}$ of agar per liter of water.

Isolation and identification of $F$. asiaticum and $F$. graminearum. Wheat samples were collected from commercial wheat fields in Anhui Province, where pyraclostrobin and epoxiconazole had likely never been used. The climate in the regions is humid and subtropical. The samples were collected during the harvest season of 2010 and 2011. Identification of $F$. asiaticum and F. graminearum species is described by Suga et al (23). In total, 126 and 63 single-spore isolates of $F$. asiaticum and $F$. graminearum, respectively, were purified and collected from the samples. Among these isolates, $25 \mathrm{~F}$. asiaticum isolates were confirmed with resistance to $\mathrm{MBC}$, and all the $F$. graminearum isolates were sensitive to $\mathrm{MBC}$ based on the previous study (28).

Determination of sensitivity of growth to pyraclostrobin and epoxiconazole. To evaluate the sensitivity of mycelial growth to pyraclostrobin and epoxiconazole, the $126 \mathrm{~F}$. asiaticum isolates and $63 \mathrm{~F}$. graminearum isolates were used to determine the concentration of the fungicide causing a $50 \%$ reduction in the growth rate compared with an unamended control ( $\mathrm{EC}_{50}$ values). Autoclaved PSA was amended with pyraclostrobin or epoxiconazole to obtain final concentrations of $0,0.0125,0.025,0.05,0.1$, $0.2,0.4$, and $0.8 \mu \mathrm{g} / \mathrm{ml}$. Sensitivity tests for pyraclostrobin were conducted in the presence of salicylhydroxamic acid (SHAM), a specific inhibitor of alternative oxidase $(29,30)$. The final concentration of SHAM (Sigma, China) was $100 \mu \mathrm{g} / \mathrm{ml}$ for each fungicide treatment. An inverted mycelial plug ( $5 \mathrm{~mm}$ in diameter), cut from the edge of a 3-day-old colony, was transferred to 9 -cm petri dishes containing the amended media. Three replicates per concentration were used and all the tests were repeated twice. The mycelial growth was measured after 3 days of incubation at $25^{\circ} \mathrm{C}$ in a growth chamber (12-h photoperiod). Two perpendicular diameters of each fungal colony were measured and averaged (the diameter of the plug was subtracted). The $\mathrm{EC}_{50}$ values were determined by probit analysis (5).

Determination of sensitivity of conidium germination to pyraclostrobin. Pyraclostrobin was added to WA after sterilization to produce the concentrations of $0,0.01,0.02,0.04,0.1,0.2$, and $0.8 \mu \mathrm{g} / \mathrm{ml}$. Sensitivity tests were also conducted in the presence of SHAM at a concentration of $100 \mu \mathrm{g} / \mathrm{ml}$. Conidium suspensions containing $10^{5}$ conidia/ml derived from shake culture at $150 \mathrm{rpm}$ and $25^{\circ} \mathrm{C}$ for 5 to 7 days in $\mathrm{MBB}$ were poured onto the surface of WA plates. Conidia were allowed to germinate at $25^{\circ} \mathrm{C}$ for $8 \mathrm{~h}$. Germination was quantified at three sites by counting 100 conidia per site. A conidium was scored germinated if the germ tube had reached at least half the length of the conidium. Three plates for each concentration were used, and the experiment was performed twice. For each isolate, a linear regression of the percent inhibition relative to the control of spore germination versus the $\log _{10}$ transformation for each of the seven concentrations of pyraclostrobin was obtained. $\mathrm{EC}_{50}$, which was the fungicide concentration that resulted in $50 \%$ spore germination inhibition, was calculated with the regression equation for each isolate as described previously $(29,30)$.

Cross-resistance patterns between $\mathrm{MBC}$ and pyraclostrobin or epoxiconazole. Sensitivity to MBC of the isolates used in this study was tested through a discriminatory dose test $(7,28)$. Twelve
F. asiaticum isolates with differential sensitivity to MBC were arbitrarily chosen for the cross-resistance analysis. The 12 isolates which were sensitive or resistant to $\mathrm{MBC}$ were compared regarding their sensitivity to pyraclostrobin and epoxiconazole $\left(\mathrm{EC}_{50}\right)$ to determine cross-resistance between MBC and pyraclostrobin or epoxiconazole, as described previously (30). This experiment was performed twice.

Evaluation of protective and curative activity of pyraclostrobin and epoxiconazole against FHB. The $F$. asiaticum isolate GZ01, which was resistant to $\mathrm{MBC}$, with stable pathogenicity on wheat (unpublished data), was used for inoculation on wheat plants in the protective and curative activity tests. To prepare inoculums of conidium suspension, the actively growing mycelial plugs from PSA plates were transferred to MBB for shake culture (150 rpm) at $25^{\circ} \mathrm{C}$ for 7 days, and the conidium suspensions were adjusted to $10^{6}$ conidia/ml by centrifugation. The experiment was performed in a wheat experimental field which was known to be naturally infested with $F$. graminearum complex, in Anhui Academy of Agricultural Sciences. The wheat field was divided into 24 plots and each plot was 0.5 by $0.5 \mathrm{~m}^{2}$ and included at least 40 wheat plants. Each of the plots was separated by a $30-\mathrm{cm}$ interval with untreated wheat plants.

To evaluate the protective and curative activity of pyraclostrobin and epoxiconazole, wheat plants (Huamai number 1, a susceptible wheat cultivar) were inoculated by injecting $10 \mu \mathrm{l}$ of conidium suspension into a flowering grain in the middle of the spike. A minimum of 40 spikes per treatment were inoculated. The six treatments were: treatments 1 and 2, pyraclostrobin EC (25\% Cabrio) commercial formulation applied at 200 and $300 \mu \mathrm{g} / \mathrm{ml}$; treatments 3 and 4, epoxiconazole SC (12.5\% Opus) commercial formulation applied at 200 and $300 \mu \mathrm{g} / \mathrm{ml}$; treatment 5, 50\% MBC WG commercial formulation applied at $750 \mu \mathrm{g} / \mathrm{ml}$; and treatment 6 , no treatment control $(\mathrm{CK})$. Treatments were replicated four times and the randomized completed block design was laid out for the arrangement of the 24 plots. The experiment was repeated twice. No other fungicides were applied to the experimental plots. Other crop needs, such as fertilizers, used standard farm products. The wheat plants were at anthesis growth stage when sprayed with fungicides. Treatments were applied 24, $48 \mathrm{~h}$ and $72 \mathrm{~h}$ before (protective treatments) and after (curative treatments) inoculation. Visual disease assessment was made 14 days after the inoculation. The severity of scabbed wheat heads was assessed using a scale as described by previous studies $(13,24)$, with eight evaluation classes $(0,2,5,10$, $25,50,75$, and $90 \%$ area infected) and by applying the following formula: number of heads in each class $x$ each evaluation class/total number of heads. Efficacy percentage was determined by applying Abbott's formula: (\% infection control - \% treated infection) $/ \%$ infection control $\times 100$ (13). The experiment was performed twice.

Field trial for pyraclostrobin and epoxiconazole in controlling FHB. Winter wheat 'Yannong 19', a cultivar susceptible to FHB, was sown in fields located in Bengbu city and Chuzhou city, Anhui Province, where MBC resistance has been reported, during wheat growth seasons of 2010 and 2011. The two fields were known to be naturally infested with $F$. graminearum isolates. Each of the fields was divided into 28 plots and each plot had an area of $30 \mathrm{~m}^{2}$ ( 5 by $6 \mathrm{~m}$ ). Each of the plots was separated by a $50-\mathrm{cm}$ interval with untreated wheat plants. The seven treatments were: treatments 1 and 2, pyraclostrobin EC (25\% Cabrio) commercial formulation applied at 150 and $225 \mathrm{~g}$ a.i. ha ${ }^{-1}$; treatments 3 and 4 , epoxiconazole SC (12.5\% Opus) commercial formulation applied at 150 and $225 \mathrm{~g}$ a.i. $\mathrm{ha}^{-1}$; treatment $5,50 \%$ MBC WG commercial formulation applied at $562.5 \mathrm{~g}$ a.i. $\mathrm{ha}^{-1}$; treatment 6 , a blend of pyraclostrobin EC (25\% Cabrio) + epoxiconazole SC $(12.5 \%$ Opus) commercial formulations applied at $150+150 \mathrm{~g}$ a.i. $\mathrm{ha}^{-1}$; and treatment 7 , no treatment control $(\mathrm{CK})$. The volume of water delivered was 750 liters/ha. The cultivar was planted following the same agronomic practice. Fungicides were applied upon initiation of flowering at Feekes growth stage (GS) 10.5.1, anthesis. The sprayer was a Jacto Heavy-Duty HD400 (Agrolex, Singapore) with 
a nozzle diameter of $1.0 \mathrm{~mm}$ and operating pressure of 4 to 5 $\mathrm{kg} / \mathrm{cm}^{2}$. Treatment plots were laid out as a randomized complete block design with four replicates. No other fungicides were applied to the experimental plots. All the other crop needs, such as herbicides and fertilizers, used standard farm products. Visual disease assessment was made at least 14 days after fungicide application based on the percentage of ears exhibiting disease symptoms. Efficacies of products for FHB in the field was evaluated based on a 100-head sample collected from each plot. The percentage of diseased heads and the infected area of the head were determined for each plot. The disease severity and fungicide efficacy were reported as previously described $(13,24)$.

Data analysis. Data from repeated experiments were combined for analysis because variances between experiments were homogeneous. All data were processed with the SIGMASTAT Statistical Software Package (version 11; SPSS Science). EC $_{50}$ values were calculated from the sensitivity tests described above from the fitted regression line of the probit of the percent inhibition plotted against the log-transformed fungicide concentration (6).

\section{Results}

Sensitivity of growth to pyraclostrobin and epoxiconazole. The $\mathrm{EC}_{50}$ values for pyraclostrobin in inhibiting mycelial growth of the $126 \mathrm{~F}$. asiaticum isolates and $63 \mathrm{~F}$. graminearum isolates on PSA plates were 0.012 to 0.135 and 0.010 to $0.105 \mu \mathrm{g} / \mathrm{ml}$, respectively, with average $\mathrm{EC}_{50}$ values of $0.064 \pm 0.028$ and $0.052 \pm$ $0.017 \mu \mathrm{g} / \mathrm{ml}$, respectively (Fig. 1A and B). Both of the two baseline sensitivity curves were unimodal (Fig. 1A and B), representing range-of-variation factors of 11.25 and 10.50 for $F$. asiaticum and F. graminearum, respectively.

The $\mathrm{EC}_{50}$ values for epoxiconazole in inhibiting mycelial growth of the $F$. asiaticum and $F$. graminearum populations on PSA plates were 0.12 to 0.95 and 0.16 to $0.93 \mu \mathrm{g} / \mathrm{ml}$, respectively, with the average $\mathrm{EC}_{50}$ values of $0.46 \pm 0.18$ and $0.42 \pm 0.13 \mu \mathrm{g} / \mathrm{ml}$, respectively (Fig. 2A and B). Both of the two baseline sensitivity curves were also unimodal (Fig. 2A and B), representing range-of-variation factors of 7.92 and 5.81 for $F$. asiaticum and F. graminearum, respectively.
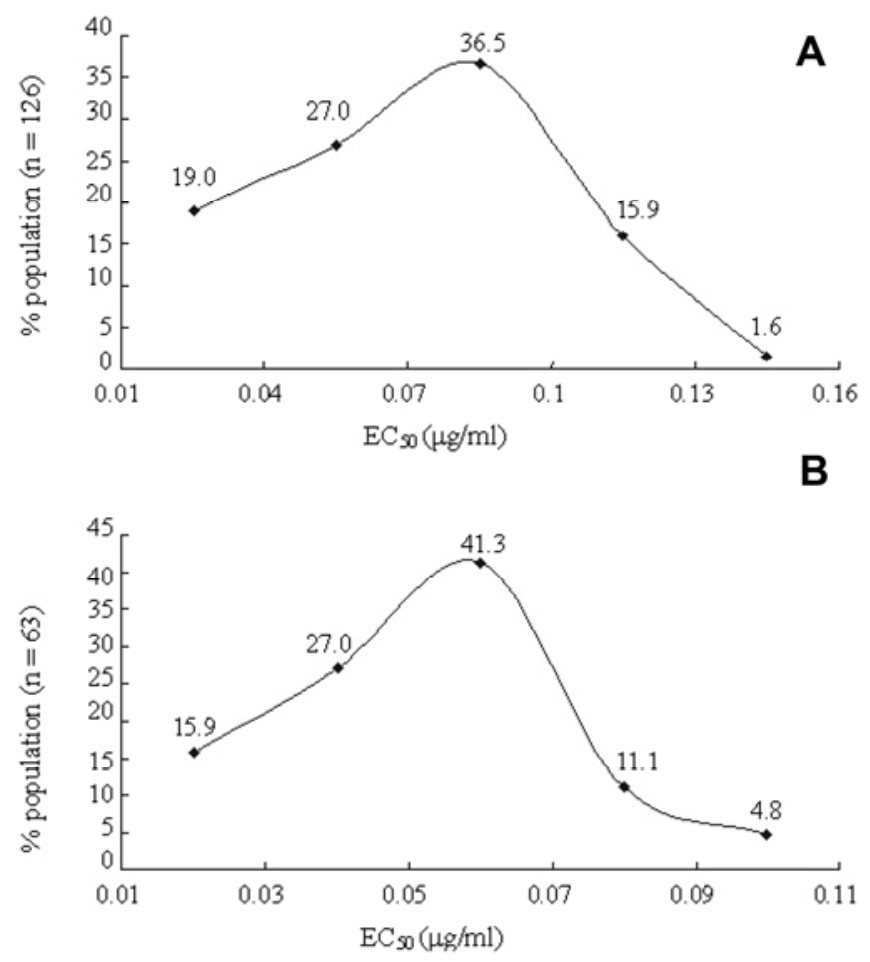

Fig. 1. Frequency distribution of sensitivity of mycelial growth (baseline sensitivity) of A, Fusarium asiaticum and B, F. graminearum to pyraclostrobin (in the presence of salicylhydroxamic acid).
In the presence of SHAM, pyraclostrobin exhibited stronger inhibitory activity against mycelial growth of $F$. asiaticum isolates and $F$. graminearum than that of epoxiconazole. The sensitivity data can be used as baselines for monitoring any future changes in sensitivity to pyraclostrobin and epoxiconazole by F. asiaticum and $F$. graminearum populations. Such baseline data are essential for assessing resistance risk, managing field-resistance, and monitoring resistance levels in the pathogen populations.

Sensitivity of conidium germination to pyraclostrobin. The $\mathrm{EC}_{50}$ values for pyraclostrobin in inhibiting conidium germination on WA plates of the $F$. asiaticum and $F$. graminearum populations were 0.047 to 0.291 and 0.042 to $0.255 \mu \mathrm{g} / \mathrm{ml}$, respectively, with the average $\mathrm{EC}_{50}$ values of $0.102 \pm 0.041$ and $0.117 \pm 0.055 \mu \mathrm{g} / \mathrm{ml}$, respectively (Fig. 3A and B). Both of the two baseline sensitivity curves were unimodal (Fig. 3A and B), representing range-ofvariation factors of 6.19 and 6.07 for F. asiaticum and F. graminearum, respectively. These data indicated that conidium germination of $F$. asiaticum and $F$. graminearum was very sensitive to pyraclostrobin. This baseline data would also be essential for monitoring any further insensitivity or resistance to pyraclostrobin in $F$. asiaticum and $F$. graminearum isolates.

Cross-resistance patterns. There was significant difference $(P$ $=0.05)$ in sensitivity to pyraclostrobin or epoxiconazole between MBC-sensitive and -resistant isolates based on the $\mathrm{EC}_{50}$ values (Table 1). However, there was no correlation between this difference in sensitivity to $\mathrm{MBC}$ and pyraclostrobin or epoxiconazole. This suggests that there is no cross-resistance between MBC and pyraclostrobin or epoxiconazole.

Protective and curative activity of pyraclostrobin and epoxiconazole against FHB. When the fungicides were applied 1, 3, and 5 days before inoculations, the average control efficacy of pyraclostrobin at 200 or $300 \mu \mathrm{g} / \mathrm{ml}$ was more than $80 \%$ in all cases, indicating excellent protective activity against FHB. Moreover, epoxiconazole applied at 200 or $300 \mu \mathrm{g} / \mathrm{ml}$ provided 78.2 to $89.8 \%$ protective control efficacy (Table 2). Unfortunately, MBC applied at $750 \mu \mathrm{g} / \mathrm{ml}$ provided significantly less protective control efficacy than pyraclostrobin or epoxiconazole in corresponding treatments (Table 2).

Also, pyraclostrobin applied 1 and 3 days after inoculations at 200 or $300 \mu \mathrm{g} / \mathrm{ml}$ exhibited over $80 \%$ curative control efficacy
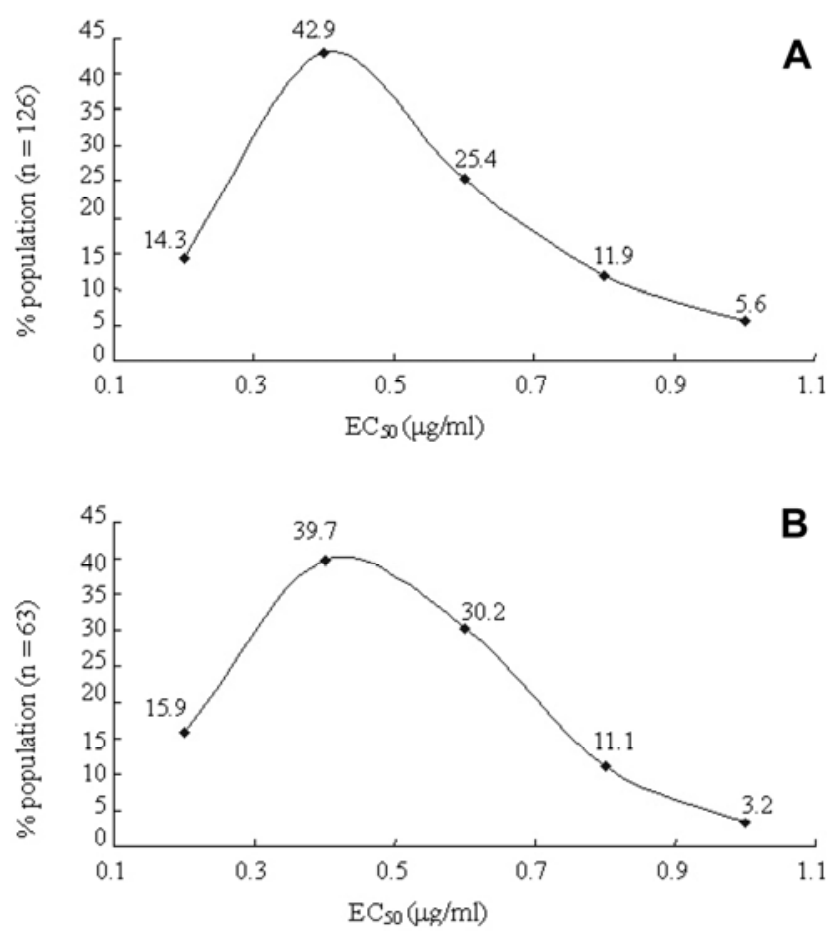

Fig. 2. Frequency distribution of sensitivity of mycelial growth (baseline sensitivity) of A, Fusarium asiaticum and B, F. graminearum to epoxiconazole. 
against FHB but less than $80 \%$ curative control efficacy when applied 5 days after inoculations (Table 2). However, in all cases, epoxiconazole applied at 200 or $300 \mu \mathrm{g} / \mathrm{ml}$ provided excellent curative control efficacy of over $80 \%$ (Table 2). Worse still, MBC applied at $750 \mu \mathrm{g} / \mathrm{ml}$ exhibited less than $70 \%$ curative control efficacy in each treatment (Table 2).

Control efficacy of pyraclostrobin and epoxiconazole in wheat fields. The incidence of FHB at both sites was correlated with moisture period during the flowering stage. In the two sites, both pyraclostrobin and epoxiconazole at $225 \mathrm{~g}$ a.i./ha provided over $80 \%$ control efficacy in 2010 and 2011, suggesting excellent activity against FHB (Table 3). Also, control efficacy of pyraclostrobin and epoxiconazole at $150 \mathrm{~g}$ a.i./ha at both sites was greater than $70 \%$, which was significantly higher than that of MBC applied at $562.5 \mathrm{~g}$ a.i./ha (Table 3). Interestingly, integrated use of pyraclostrobin + epoxiconazole applied at $150+150 \mathrm{~g}$ a.i./ha provided over $85 \%$ control efficacy at both sites in 2010 and 2011,
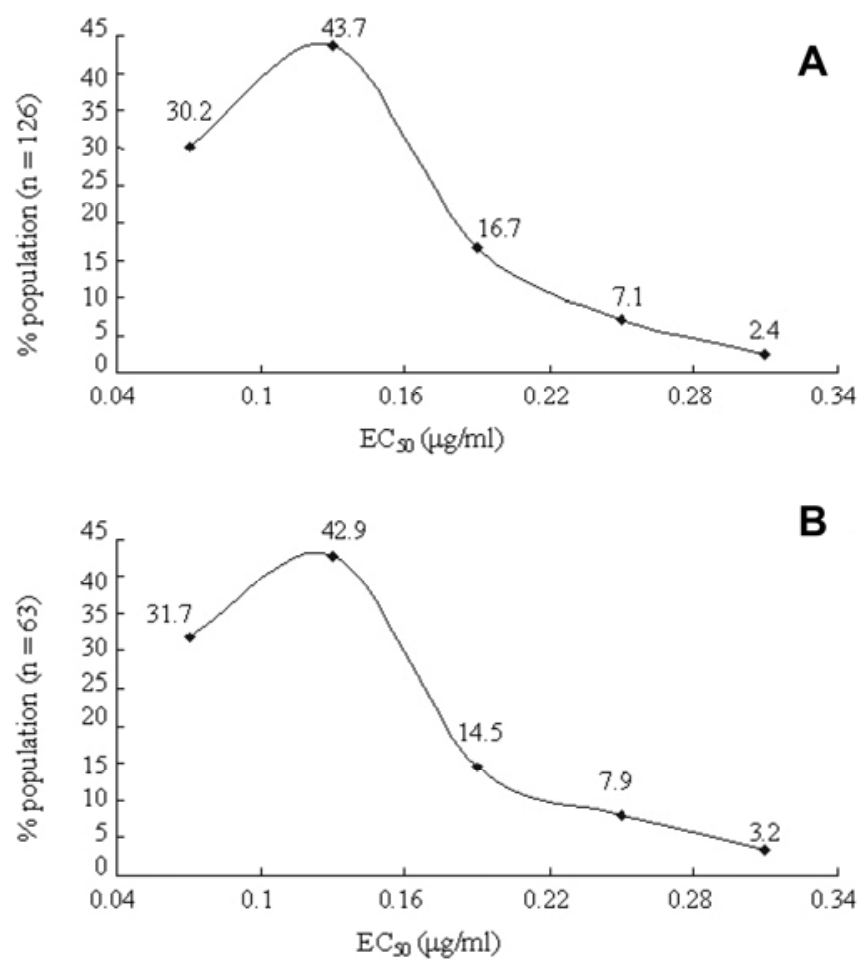

Fig. 3. Frequency distribution of sensitivity of conidium germination (baseline sensitivity) of A, Fusarium asiaticum and B, F. graminearum to pyraclostrobin (in the presence of salicylhydroxamic acid). which was significantly better than those of other treatments in the field trials (Table 3 ).

\section{Discussion}

Application of fungicide for managing FHB has been relied upon over the last few decades, because few cultivars with effective genetic resistance are available. The benzimidazole fungicides, particularly MBC, have been routinely used for more than 30 years during each period of wheat heading and flowering, in areas with warm and moist weather, to control FHB in China (32). A distinct advantage of $\mathrm{MBC}$ was its systemic activity which not only protected plants from infection but also provided disease control when applied after the early stages of infection. However, based on MBC-resistance monitoring, the frequency of resistant isolates in some regions of China increased gradually, and the efficacy of MBC against FHB decreased dramatically after 1998 (6). In a sense, the effectiveness of $\mathrm{MBC}$ was reduced due to the selection of a resistant pathogen population in the field (28). Because of this selection for resistance, China now is facing a challenge to find alternative fungicides for managing FHB on wheat. Therefore, introduction of an alternative fungicide with a different mode of action for MBC resistance and consistent control of FHB is urgent. In theory, when fungicides are introduced with specific targets to control, each of the targets requires a baseline sensitivity to be established so that product use strategies can be monitored and future resistance can be detected (19). The mode of actions of pyraclostrobin (a QoI) and epoxiconazole (a DMI), which were not widely used for the control of FHB in China, have been proven to be different from that of MBC (a benzimidazole fungicide). This study also suggested that there was no cross-resistance between MBC and pyraclostrobin or epoxiconazole. This could be explained by the difference in mode of action between MBC, pyraclostrobin, or epoxiconazole (Table 1). Previous studies showed that the spore germination of fungal pathogens was always more sensitive to QoI fungicides than that of mycelial growth, and protective use of these fungicides exhibited greater control efficacy for fungal diseases in plants (12). In this study, pyraclostrobin showed strong antifungal activity of inhibiting both mycelial growth and conidium germination in the presence of SHAM (Table 1). Some plant antioxidants, such as flavone presented in the host, quenched the active oxygen species from reaching the level sufficient for inducing an alternative oxidase pathway during QoI action, playing a role similar to SHAM (12). In fact, our study has shown that SHAM greatly improved the activity of pyraclostrobin against mycelial growth and conidial germination of $F$. graminearum isolates (data not shown). Nevertheless, the presence of SHAM would favorably exhibit the activity of pyraclostrobin in the in vitro test.

In this study, the baseline sensitivities of $F$. asiaticum and $F$. graminearum isolates to pyraclostrobin and epoxiconazole were also

Table 1. Cross-resistance between carbendazim and pyraclostrobin or epoxiconazole in Fusarium asiaticum

\begin{tabular}{|c|c|c|c|c|}
\hline \multirow[b]{3}{*}{ Isolates } & \multirow[b]{3}{*}{ Sensitivity to carbendazim ${ }^{z}$} & \multicolumn{3}{|c|}{$\mathrm{EC}_{50}$ for $^{\mathrm{y}}$} \\
\hline & & \multicolumn{2}{|c|}{ Pyraclostrobin $(\mu \mathrm{g} / \mathrm{ml})$} & \multirow{2}{*}{$\begin{array}{c}\text { Epoxiconazole }(\mu \mathrm{g} / \mathrm{ml}) \\
\text { Inhibiting growth }\end{array}$} \\
\hline & & Inhibiting growth & Inhibiting germination & \\
\hline TTZ01 & $\mathrm{S}$ & $0.052 \mathrm{f}$ & $0.122 \mathrm{a}$ & $0.323 \mathrm{k}$ \\
\hline TTZ02 & $\mathrm{S}$ & $0.054 \mathrm{f}$ & 0.077 cde & $0.581 \mathrm{f}$ \\
\hline TTZ03 & $\mathrm{S}$ & 0.058 ef & $0.072 \mathrm{ef}$ & $0.622 \mathrm{e}$ \\
\hline LJ09 & $\mathrm{S}$ & $0.082 \mathrm{bc}$ & $0.052 \mathrm{~g}$ & $0.763 \mathrm{~b}$ \\
\hline LJ13 & $\mathrm{S}$ & $0.074 \mathrm{~cd}$ & $0.091 \mathrm{bcd}$ & $0.535 \mathrm{~g}$ \\
\hline LK07 & $\mathrm{S}$ & $0.088 \mathrm{ab}$ & $0.064 \mathrm{efg}$ & $0.852 \mathrm{a}$ \\
\hline FY01 & $\mathrm{R}$ & $0.068 \mathrm{~d}$ & $0.092 \mathrm{bc}$ & $0.427 \mathrm{~h}$ \\
\hline FY03 & $\mathrm{R}$ & $0.092 \mathrm{a}$ & $0.062 \mathrm{efg}$ & $0.393 \mathrm{j}$ \\
\hline FY06 & $\mathrm{R}$ & $0.072 \mathrm{~d}$ & $0.106 a b$ & $0.715 \mathrm{c}$ \\
\hline GZ02 & $\mathrm{R}$ & $0.066 \mathrm{de}$ & $0.057 \mathrm{fg}$ & $0.577 \mathrm{f}$ \\
\hline GZ06 & $\mathrm{R}$ & $0.055 \mathrm{f}$ & $0.100 \mathrm{~b}$ & $0.412 \mathrm{i}$ \\
\hline GZ08 & $\mathrm{R}$ & $0.067 \mathrm{~d}$ & $0.074 \mathrm{def}$ & $0.646 \mathrm{~d}$ \\
\hline
\end{tabular}

${ }^{\mathrm{y}} \mathrm{EC}_{50}=50 \%$ effective concentration. Mean values with the same letters within the same column were not significantly different with a least significant difference test at $P=0.05$.

${ }^{\mathrm{z}} \mathrm{S}$ and $\mathrm{R}$ indicate sensitive and resistant, respectively, to carbendazim. 
established. The results showed that the selected isolates were very sensitive to these two fungicides and the low values and the relatively short range of sensitivity variation indicated the absence of resistant subpopulations among the isolates used in this study. Therefore, the sensitivity data can be used as baseline sensitivity for monitoring any future changes in sensitivity to pyraclostrobin and epoxiconazole in $F$. asiaticum and $F$. graminearum populations. Such baseline data are essential for assessing resistance risk, managing field resistance, and monitoring resistance levels in the pathogen populations.

In the protective and curative tests, pyraclostrobin applied at 200 and $300 \mu \mathrm{g} / \mathrm{ml}$ exhibited higher protective control efficacy than that of epoxiconazole applied at 200 and $300 \mu \mathrm{g} / \mathrm{ml}$ (Table 2 ). This could be explained by the specific activity of pyraclostrobin against conidium germination by inhibiting delivery of electrons for energy production $(10,12)$. However, in the curative tests, epoxiconazole applied at 200 and $300 \mu \mathrm{g} / \mathrm{ml}$ exhibited over $80 \%$ curative control efficacy, indicating stable activity against FHB (Table 2). Therefore, integrated use of pyraclostrobin + epoxiconazole might provide ideal control of FHB. This was further confirmed by field trials in this study. The results of field trials showed that integrated use of pyraclostrobin + epoxiconazole applied at $150+150 \mathrm{~g}$ a.i./ha provided over $85 \%$ control efficacy at both sites in 2010 and 2011, an increase compared with other treatments in the field trials (Table 3). In addition, single use of pyraclostrobin or epoxiconazole applied at
150 and $225 \mathrm{~g}$ a.i./ha at both sites also provided over 70 and $80 \%$ control efficacy, respectively, against FHB (Table 3). MBC applied at $562.5 \mathrm{~g}$ a.i./ha in all cases only provided less than $67 \%$ control efficacy (Table 3 ).

To our knowledge, the present study is the first report on the baseline sensitivity of Chinese $F$. asiaticum and $F$. graminearum populations to pyraclostrobin and epoxiconazole and the excellent protective and curative efficacy of these two fungicides in controlling FHB. Taken together, pyraclostrobin and epoxiconazole should be good alternatives to MBC for the control of FHB. However, this does not mean that pyraclostrobin and epoxiconazole could be extensively used for disease control because these two QoIs and DMIs are also at-risk fungicides, and resistance to QoIs and DMIs has already reported in previous studies $(1,9,11,16,29)$. Therefore, these two fungicides should be carefully used, such as alternative applications or tank-mixing with other effective fungicides with different modes of action.

\section{Acknowledgments}

This study was sponsored by (i) key projects in the national science and technology pillar program during the 12th five-year plan period (numbers 2011BAD16B06 and 2012BAD04B09), (ii) a special fund for agro-scientific research in the public interest from the ministry of agriculture, China (number 200903033), (iii) Anhui Provincial Natural Science Foundation (No. 10040606Q26), (iv) 2012 Dean Younth Innovation Fund of Anhui Academy of Agricultural Sciences (12B1121), and (v) Innovation Team of Anhui Academy of Agricultural Sciences (12C1105).

Table 2. Protective and curative activity of pyraclostrobin and epoxiconazole against Fusarium head blight of wheat

\begin{tabular}{|c|c|c|c|c|c|c|c|}
\hline \multirow[b]{3}{*}{ Treatment $^{\mathrm{z}}$} & \multirow[b]{3}{*}{ Dosage $\left(\mu \mathrm{g} \mathrm{ml}^{-1}\right)$} & \multicolumn{6}{|c|}{ Average disease severity $(\%)^{y}$} \\
\hline & & \multicolumn{3}{|c|}{ Protective activity } & \multicolumn{3}{|c|}{ Curative activity } \\
\hline & & 1 day & 3 days & 5 days & 1 days & 3 days & 5 days \\
\hline \multirow[t]{2}{*}{$25 \%$ pyraclostrobin EC } & 200 & $3.82 \mathrm{c}$ & $4.53 \mathrm{~cd}$ & $5.93 \mathrm{c}$ & $3.57 \mathrm{~d}$ & $5.16 \mathrm{c}$ & $7.52 \mathrm{c}$ \\
\hline & 300 & $2.56 \mathrm{~d}$ & $3.46 \mathrm{~d}$ & $4.69 \mathrm{~d}$ & $2.62 \mathrm{e}$ & $3.81 \mathrm{~d}$ & $7.01 \mathrm{~d}$ \\
\hline \multirow[t]{2}{*}{$12.5 \%$ epoxiconazole $\mathrm{SC}$} & 200 & $4.45 \mathrm{c}$ & $5.75 \mathrm{c}$ & $6.31 \mathrm{c}$ & $4.65 \mathrm{c}$ & $3.97 \mathrm{~d}$ & $5.88 \mathrm{e}$ \\
\hline & 300 & $2.91 \mathrm{~d}$ & $4.27 \mathrm{~cd}$ & $6.52 \mathrm{c}$ & $2.78 \mathrm{e}$ & $2.75 \mathrm{e}$ & $5.31 \mathrm{e}$ \\
\hline $50 \%$ carbendazim WG & 750 & $9.86 \mathrm{~b}$ & $10.52 \mathrm{~b}$ & $11.68 \mathrm{~b}$ & $11.73 \mathrm{~b}$ & $10.63 \mathrm{~b}$ & $10.17 \mathrm{~b}$ \\
\hline $\mathrm{CK}$ & $\ldots$ & $28.63 \mathrm{a}$ & $32.64 \mathrm{a}$ & $29.92 \mathrm{a}$ & $31.13 \mathrm{a}$ & $27.86 \mathrm{a}$ & $30.35 \mathrm{a}$ \\
\hline
\end{tabular}

y Visual disease assessment was made 14 days after inoculation. The severity of scabbed wheat heads was assessed using a scale as described by previous studies $(13,24)$, with eight evaluation classes $(0,2,5,10,25,50,75$, and $90 \%$ area infected) by applying the following formula: number of heads in each class $\times$ each evaluation class/total number of heads. Efficacy percentage was determined by applying Abbott's formula: (\% infection control - \% treated infection $) / \%$ infection control $\times 100$. Mean values with the same letters within the same column were not significantly different $(P>0.05$, Fisher's least significant difference).

${ }^{\mathrm{z}} \mathrm{EC}, \mathrm{SC}$, WG, and CK represent emulsifiable concentrates, suspension concentrates, water-dispersible granules, and aqueous solutions, respectively.

Table 3. Efficacy of pyraclostrobin and epoxiconazole in controlling Fusarium head blight of wheat

\begin{tabular}{|c|c|c|c|c|c|}
\hline \multirow[b]{2}{*}{ Site, treatment ${ }^{\mathrm{z}}$} & \multirow[b]{2}{*}{ Dosage (g a.i/ha) } & \multicolumn{2}{|c|}{ Average disease severity $(\%)$} & \multicolumn{2}{|c|}{ Control efficacy (\%) } \\
\hline & & 2010 & 2011 & 2010 & 2011 \\
\hline \multicolumn{6}{|l|}{ Chuzhou City } \\
\hline \multirow[t]{2}{*}{$25 \%$ pyraclostrobin EC } & 150 & 2.68 & 0.97 & $75.5 \mathrm{c}$ & $71.1 \mathrm{c}$ \\
\hline & 225 & 1.79 & 0.66 & $83.7 \mathrm{~b}$ & $80.4 \mathrm{~b}$ \\
\hline \multirow[t]{2}{*}{$12.5 \%$ epoxiconazole SC } & 150 & 2.77 & 0.94 & $74.7 \mathrm{c}$ & $72.0 \mathrm{c}$ \\
\hline & 225 & 1.92 & 0.62 & $82.5 \mathrm{~b}$ & $81.5 \mathrm{~b}$ \\
\hline $25 \%$ pyraclostrobin $\mathrm{EC}+12.5 \%$ epoxiconazole $\mathrm{SC}$ & $150+150$ & 1.25 & 0.42 & $88.6 \mathrm{a}$ & $87.5 \mathrm{a}$ \\
\hline $50 \%$ carbendazim WG & 562.5 & 3.69 & 1.32 & $66.3 \mathrm{~d}$ & $60.7 \mathrm{~d}$ \\
\hline CK & $\ldots$ & 10.96 & 3.36 & $\ldots$ & $\ldots$ \\
\hline \multicolumn{6}{|l|}{ Bengbu City } \\
\hline \multirow[t]{2}{*}{$25 \%$ pyraclostrobin $\mathrm{EC}$} & 150 & 3.96 & 1.31 & $75.1 \mathrm{c}$ & $71.3 \mathrm{c}$ \\
\hline & 225 & 2.74 & 0.86 & $82.8 \mathrm{~b}$ & $81.1 \mathrm{~b}$ \\
\hline \multirow[t]{2}{*}{$12.5 \%$ epoxiconazole SC } & 150 & 3.88 & 1.15 & $75.8 \mathrm{c}$ & $74.8 \mathrm{c}$ \\
\hline & 225 & 2.89 & 0.90 & $81.9 \mathrm{~b}$ & $80.2 \mathrm{~b}$ \\
\hline $25 \%$ pyraclostrobin $\mathrm{EC}+12.5 \%$ epoxiconazole $\mathrm{SC}$ & $150+150$ & 1.96 & 0.63 & $87.7 \mathrm{a}$ & $86.2 \mathrm{a}$ \\
\hline $50 \%$ carbendazim WG & 562.5 & 6.05 & 1.72 & $62.0 \mathrm{~d}$ & $62.3 \mathrm{~d}$ \\
\hline CK & $\ldots$ & 15.93 & 4.56 & $\ldots$ & $\ldots$ \\
\hline
\end{tabular}

y Visual disease assessment was made at least 14 days after inoculation. The severity of scabbed wheat heads was assessed using a scale as described by previous studies $(13,24)$, with eight evaluation classes $(0,2,5,10,25,50,75$, and $90 \%$ area infected) by applying the following formula: number of heads in each class $\times$ each evaluation class/total number of heads. Efficacy percentage was determined by applying Abbott's formula: $(\%$ infection control $-\%$ treated infection $) / \%$ infection control $\times 100$. Mean values with the same letters within the same column were not significantly different $(P>0.05$, Fisher's least significant difference).

${ }^{\text {z }}$ EC, SC, WG, and CK represent emulsifiable concentrates, suspension concentrates, water-dispersible granules, and aqueous solutions, respectively. 


\section{Literature Cited}

1. Avenot, H., Morgan, D. P., and Michailides, T. J. 2008. Resistance to pyraclostrobin, boscalid and multiple resistance to Pristine (pyraclostrobin + boscalid) fungicide in Alternaria alternata causing Alternaria late blight of pistachios in California. Plant Pathol. 57:135-140.

2. Bai, G., and Shaner, G. 1994. Scab of wheat: Prospects for control. Plant Dis. 78:760-766.

3. Carter, J. P., Rezanoor, H. N., Holden, D., Desjardins, A. E., Plattner, R. D., and Nicholson, P. 2002. Variation in pathogenicity associated with the genetic diversity of Fusarium graminearum. Eur. J. Plant Pathol. 108:573583.

4. Chen, C. J., Yu, J. J., Bi, C. W., Zhang, Y. N., Xu, J. Q., Wang, J. X., and Zhou, M. G. 2009. Mutations in a $\beta$-tubulin confer resistance of Gibberella zeae to benzimidazole fungicides. Phytopathology 99:1403-1411.

5. Chen, Y., Chen, C. J., Zhou, M. G., Wang, J. X., and Zhang, W. Z. 2009. Monogenic resistance to a new fungicide JS399-19 in Gibberella zeae. Plant Pathol. 58:565-570.

6. Chen, Y., Li, H., Chen, C., and Zhou, M. 2008. Sensitivity of Fusarium graminearum to fungicide JS399-19: In vitro determination of baseline sensitivity and the risk of developing fungicide resistance. Phytoparasitica 36:326-337.

7. Chen, Y., Wang, J. X., Zhou, M. G., Chen, C. J., and Yuan, S. K. 2007. Vegetative compatibility of Fusarium graminearum isolates and genetic study on their carbendazim-resistance recombination in China. Phytopathology 97:1584-1589.

8. Chen, Y., and Zhou, M.-G. 2009. Characterization of Fusarium graminearum isolates resistant to both carbendazim and a new fungicide JS399-19. Phytopathology 99:441-446.

9. Cox, K. D., Bryson, P. K., and Schnabel, G. 2007. Instability of propiconazole resistance and fitness in Monilinia fructicola. Phytopathology 97:448-453.

10. Esser, L., Quinn, B., Li, Y. F., Zhang, M. Q., Elberry, M., Yu, L. D., Yu, C. A., and Xia, D. 2004. Crystallographic studies of quinol oxidation site inhibitors: A modified classification of inhibitors for the cytochrome bc1 complex. J. Mol. Biol. 341:281-302.

11. Jiang J., Ding L., Michailides T. J., Li H., and Ma Z. 2009. Molecular characterization of field azoxystrobin-resistant isolates of Botrytis cinerea. Pestic. Biochem. Physiol. 93:72-76.

12. Jin L., Chen Y., Chen C., Wang J., and Zhou M. 2009. Activity of azoxystrobin and SHAM to four phytopathogens. Agric. Sci. Chin. 8:835-842.

13. Li, H., Diao, Y., Wang, J., Chen, C., Ni, J., and Zhou, M. 2008. JS399-19, a new fungicide against wheat scab. Crop Prot. 27:90-95.

14. Mesterhazy, A., Bartok, T., and Lamper, C. 2003. Influence of wheat cultivar, species of Fusarium, and isolate aggressiveness on the efficiency of fungicides for control of Fusarium head blight. Plant Dis. 87:1107-1115.

15. Muellenborn, C., Steiner, U., Ludwig, M., and Oerke, E. 2008. Effect of fungicides on the complex of Fusarium species and saprophytic fungi colonizing wheat kernels. Eur. J. Plant Pathol. 120:157-166.

16. Nikou D., Malandrakis A., Konstantakaki M., Vontas J., Markoglou A., and Ziogas B. 2009. Molecular characterization and detection of overexpressed C-14 alpha-demethylase-based DMI resistance in Cercospora beticola field isolates. Pestic. Biochem. Physiol. 95:18-27.

17. Nisessen, L. 2007. PCR-based diagnosis and quantification of mycotoxin producing fungi. Int. J. Food Microbiol. 19:38-46.

18. O'Donnell, K., Ward, T. J., Geiser, D. M., Kistler, H. C., and Aokid, T. 2004. Genealogical concordance between the mating type locus and seven other nuclear genes supports formal recognition of nine phylogenetically distinct species within the Fusarium graminearum clade. Fungal Genet. Biol. 41:600-623.

19. Russell, P. E. 2004. Sensitivity baselines in fungicide resistance research and management. In: FRAC Monograph, 3. CropLife International, Brussels. www.frac.info

20. Snijders, C. H. A. 1990. Fusarium head blight and mycotoxin contamination of wheat, a review. Neth. J. Plant Pathol. 96:187-198.

21. Starkey, D. E., Ward, T. J., Aoki, T., Gale, L. R., Kistler, H. C., Geiser, D. M., Suga, H., Tóth, B., Varga, J., and O’Donnell, K. 2007. Global molecular surveillance reveals novel Fusarium head blight species and trichothecene toxin diversity. Fungal Genet. Biol. 44:1191-1204.

22. Stoyan, R. P., Simon, G. E., Martin, C. H., and Peter, J. 2003. Strategies for the control of Fusarium head blight in cereals. Eur. J. Plant Pathol. 109:731-742.

23. Suga, H., Karugia, G. W., Ward, T., Gale, L. R., Tomimura, K., Nakajima, T., Miyasaka, A., Koizumi, S., Kageyama, K., and Hyakumachi, M. 2008. Molecular characterization of the Fusarium graminearum species complex in Japan. Phytopathology 98:159-166.

24. Tomohiro, B., and Kazuhiro, S. 2000. Genetic analysis of resistance to Fusarium head blight caused by Fusarium graminearum in Chinese wheat cultivar Sumai 3 and the Japanese cultivar Saikai 165. Euphytica 113:87-99.

25. Tóth, B., Mesterházy, Á., Horváth, Z., Bartók, T., Varga, M., and Varga, J. 2005. Genetic variability of central European isolates of the Fusarium graminearum species complex. Eur. J. Plant Pathol. 113:35-45.

26. Xu, X. M., Parry, D. W., Nicholson, P., Thomsett,, M. A,, Simpson, D., Edwards, S. G., Cooke, B. M., Doohan, F. M., Monaghan, S., Moretti, A., Tocco, G., Mule, G., Hornok, L., Béki, E., Tatnell, J., and Ritieni, A. 2008. Within-field variability of Fusarium head blight pathogens and their associated mycotoxins. Eur. J. Plant Pathol. 120:21-34.

27. Yin, Y., Liu, X., Li, B., and Ma, Z. 2009. Characterization of sterol demethylation inhibitor-resistant isolates of Fusarium asiaticum and F. graminearum collected from wheat in China. Phytopathology 99:487-497.

28. Yuan, S., and Zhou, M. 2005. A major gene for resistance to carbendazim, in field isolates of Gibberella zeae. Can. J. Plant Pathol. 27:58-63.

29. Zhang, C., Liu, Y., Ding, L., Zhu, G. 2011. Shift of sensitivity of Botrytis cinerea to azoxystrobin in greenhouse vegetables before and after exposure to the fungicide. Phytoparasitica 39:293-302.

30. Zhang, C. Q., Zhang, Y., and Zhu, G. N. 2008. The mixture of kresoximmethyl and boscalid, an excellent alternative controlling grey mould caused by Botrytis cinerea. Ann. Appl. Biol. 153:205-213.

31. Zhang, J. B., Li, H. P., Dang, F. J., Qu, B., Xu, Y. B., Zhao, C. S., and Liao, Y. C. 2007. Determination of the trichothecene mycotoxin chemotypes and associated geographical distribution and phylogenetic species of the Fusarium graminearum clade from China. Mycol. Res. 111:967-975.

32. Zhou, M. G., Ye, Z. Y., and Liu, J. F. 1994. Progress of fungicide resistance. J. Nanjing Agric. Univ. 17:33-41. 